\title{
ORGANIZATIONAL COMMITMENT AND CHARACTERISTICS OF THE WORKPLACE
}

\author{
Raluca RUSU \\ "Nicolae Bălcescu” Land Forces Academy, Sibiu, Romania \\ rbalasoiu@yahoo.com
}

\begin{abstract}
In this paper we will analyze the extent to which the organizational commitment of the teaching staff is influenced by a number of factors in the category of job characteristics, namely: professional satisfaction, trust in the higher education system, global evaluation of the quality of the faculty and perception on the availability of resources learning. Following the regression model realized, the hypothesis was confirmed, according to which job satisfaction fuels attachment to the organization more than other factors.
\end{abstract}

KEYWORDS: organizational commitment, characteristics of the workplace, organizational satisfaction

\section{Introduction}

The problem of the relationship between man and organization crosses, as a red thread, the whole history of the analysis of organizations. Almost all explanatoryinterpretative models, which refer to the two entities, refer explicitly or implicitly to the nature of the relationship between man and organization, and especially to the ways of improving and optimizing it. Thus, several authors have tried to look at this relationship through various lenses, (for example: psychological contract theory, organizational support theory, congruence theory between the individual and the organization) all being based on the paradigm of social exchange, based on the idea of the norm of reciprocity between the organization and employee. There is always an "understanding" between the organization and the individual in which each one is obliged to "give" something and "receive" something else, the purpose of this exchange being to combine the organizational aims with the interests of the employees. In this context, the discussion about organizational commitment is also included.
Does the organization benefit from having a high level of organizational commitment? What is the mechanism by which commitment influences performance and what can the organization do to develop and optimize it? What are the conditions that favour the development of the commitment? Do they become loyal employees only when they have to earn from this, or does the commitment appear beyond the extrinsic motivation? These are the frame questions to which we will seek answers throughout our work. The empirical analysis will focus on a series of more specific questions, such as: what are the factors that influence the emergence of the organizational commitment and more precisely what are the characteristics of the work that favour its development?

Considering the variety of meanings found in the literature, Meyer and Allen (1991) made an inventory of existing definitions, with the purpose of constructing a unanimously accepted definition. The similarities between these definitions were the basis of the definition developed 
by them, considered to be the essence of the commitment, namely: "commitment is the force that binds the individual to an action relevant to a particular purpose... and can influence the behaviour even in the case of lack of extrinsic motivation or positive attitude" (Meyer \& Herscovitch, 2001, p. 301). We are not talking about any connection but a psychological connection that characterizes the employee's relationship with the organization and has implications on the decision to remain in the organization (Meyer \& Allen, 1997, p. 11).

\section{Determinants of Organizational Commitment}

Several authors (Mathieu \& Zajac, 1990; Meyer \& Allen, 1997) undertook investigations that identified the determinants and consequences of organizational commitment, an analysis that is due to the need to discover ways to improve the functionality of modern organizations and implicitly, the behaviour of their members.

Given that employees with a high level of organizational commitment are more valuable than those with a low level of commitment, the researchers focused on identifying the factors that determine its variation. Most authors who leaned on this topic considered three categories of factors, namely: personal characteristics, job characteristics, and organizational characteristics (Mathieu \& Zajac, 1990; Mowday, Porter \& Steers, 1982). Given that most authors support the idea that organizational commitment is influenced by organizational rather than personal factors (Meyer, Irving \& Allen, 1998), in this paper we will focus only on theoretical and empirical analysis of how a series of characteristics of the workplace are involved in their development. The explanation is related to the fact that the experiences of individuals in the workplace are mainly determined by the characteristics of the workplace.

Of these, the quality of social relationships in the organizational environment (communication quality, interpersonal trust, organizational support) has a major positive effect on organizational commitment (Watson \& Papamarcos, 2002). Regarding the link between organizational commitment and leadership style, Dobbin \& Boychuk (1999) find that engagement is higher in organizations where there is a culture of skills development, where employees are considered as human resources and not labour force. The commitment is increased if the employees have the opportunity to participate in the decision making, if they are treated with consideration and fairness (Meyer \& Allen, 1997).

Other authors, Parnell and Hatem (1997) identify as predominant variables in the explanation of organizational commitment: job satisfaction, ethical standards of leadership and perception of organizational justice. This category also includes the characteristics of the role that the individual plays in the organization. Many studies show that engagement is negatively influenced by role ambiguity and role conflict (Mathieu \& Zajac, 1990). If organizations do not take measures to remove these role problems, then the perception of employees will be that there is no organizational support and assistance, which will decrease the organizational commitment.

Studies show that there is a strong connection between the perception of organizational support and affective organizational commitment (Yoon \& Thye, 2002). The perception of organizational support refers to the belief of the employees that the organization values their contribution and that they it is concerned about their well-being (Yoon \& Thye, 2002), in other words, the commitment of the organization towards the employees.

The perception of organizational support also derives from the way in which organizational justice is managed. Rewarding employees in terms of performance and their greater participation in decision making has implications on the perception of fairness in the organization. 
Several studies support the idea that employees' perceptions of the correctness of different organizational decisions, policies and procedures have a greater influence on affective commitment than always receiving what they want (Sweeney \& McFarlin, 1993).

Challenges at the workplace and a higher level of autonomy can lead to increased confidence in personal skills and consequently the possibility of performance. Consistent with this point of view, commitment was positively correlated with participation in decision making, autonomy in carrying out work tasks, managers' receptivity to employee ideas (Mathieu \& Zajac, 1990; Meyer \& Allen, 1997).

\section{Research Methodology}

The general objective of our paper is the analysis of the organizational commitment among the teachers from the public and private higher education institutions, too, from the point of view of the factors related to the characteristics of the work that influence it. Starting from this goal, we set the following specific objective: to analyze the way in which a series of work-related experiences (perceptions and attitudes regarding work, organization and higher education system) are correlated with the overall organizational commitment.

In our study, the population universe is represented by teachers from higher education institutions, public and private in Romania. We used data collected on a representative national sample for higher education institutions, consisting of 1500 randomly selected teachers. The research method used is the sociological survey based on the questionnaire. We had the opportunity to propose, in a survey carried out by the Metro Media Transilvania institute, at the request of the Romanian Agency for Quality Assurance in Higher Education, a series of items, from the scales measuring the organizational commitment of Meyer and Allen (1991, 1997).
How did we measure work experiences? Workplace experiences refer, as Meyer and Allen (1997) show, to a range of perceptions and attitudes that individuals have regarding the workplace. We operationally translate this concept into two attitudinal variables, professional satisfaction (see also Meyer \& Allen, 1997, pp. 42-48) and trust in the university system and two variables in the sphere of perceptions, namely the overall assessment of the quality of the faculty and the perception on the availability of resources. Professional satisfaction refers to the degree to which a person is satisfied with different aspects of his/her work, such as: work place in general, relationships with colleagues, students, income level, work program, social prestige, activities performed and position in the faculty. By trusting in the university system, we understand the sense of security that teachers have that the system fulfils its social role (it provides individuals with useful skills for the labour market). The overall assessment of the quality of the university refers to the perception that the teachers have towards the value of the organization and the students. The perception of the availability of resources refers to the availability and quality of the learning resources made available by the institution.

Further on, we will present how the dependent and independent variables included in the analyzes were measured.

Organizational commitment is measured based on Meyer and Allen's (1991) model on each of the three dimensions: affective, normative and of continuity. The general question is asked as follows: "To what extent do you agree with the following statements about how you feel in your university?" Respondents indicated the degree of agreement for each statement, on a four-step scale, where the value 1 means "to a very small extent" and value 4 "to a very large extent". Affective organizational commitment (AOC) is 
measured based on the following statements: "I would be very happy to spend the rest of my career in this organization"; "I feel 'like in a family' in the organization I work in"; "I am pleased to discuss about the organization I now work with people outside of it." Organizational Commitment of Continuity (OCC) is measured based on the statements: "Many things in my life would be disturbed if I decided that I want to leave my organization now"; "I think I have too few options to consider leaving the organization I now work in", "It would be easy for me to leave the faculty I am a part of now". In the analysis the item "For me it would be easy to leave the faculty where I now work at", has been recodified so as to vary in the same sense as the others ("to a great extent" received the value 1 and "to a very small extent" the value 4). Normative organizational commitment (NOC) is measured based on the statements: "I think these days people move from one organization to another far too often"; "Loyalty is important, and therefore I feel a kind of moral obligation to remain in this organization"; "If I got a job offer elsewhere, I would feel that it is not fair to leave my organization".

The dependent variable of organizational commitment (extraction method used: Principal Axis Factoring. The explained variance: $55.73 \%$. KMO: 0.652 . The smallest community is 0.297 ) is constructed as a factorial score, based on the means of its three dimensions (NOC; AOC, OCC) (each average is calculated separately on each dimension based on the items that compose it as it appears from the confirmatory factor analysis).

How did we measure work experiences? Workplace experiences refer, as Meyer and Allen (1997) show, to a range of perceptions and attitudes that individuals have regarding the workplace. We operationally translate this concept into two attitudinal variables, professional satisfaction (Meyer \& Allen, 1997, pp. 42-48) and trust in the university system and two variables in the sphere of perceptions, namely the overall assessment of the quality of the faculty and the perception on the availability of resources. Professional satisfaction refers to the degree to which a person is satisfied with different aspects of his/her work, such as: work place in general, relationships with colleagues, students, income level, work program, social prestige, activities performed, and position in the faculty. By trusting in the university system, we understand the sense of security that teachers have that the system fulfils its social role (it provides individuals with useful skills for the labour market). The overall assessment of the quality of the university refers to the perception that the teachers have towards the value of the organization and the students. The perception of the availability of resources refers to the availability and quality of the learning resources made available by the institution.

Work satisfaction is measured on the basis of eight items that address the degree of general satisfaction with the workplace, but also with respect to different aspects of the teacher's work. The question is worded as follows: "Thinking about the university you are working in, on a scale from 0 to 10 , where 0 means very dissatisfied and 10 very satisfied how dissatisfied or satisfied you are with: work in general, the relations with colleagues, the level of income, the work program, the social prestige, the activities carried out, the position in the faculty and the relation with the students". In analyzes, job satisfaction is constructed as a factorial score.

Confidence in the university system is measured based on the answers to the following question: "How much confidence do you have in the universities of Romania regarding the preparation of students for the labour market?" The answer scale is 5 points, ranging from "very much" (value 5) to "very little" (value 1). 
The overall assessment of the quality of the faculty/university is measured as a factorial score based on four items. Three of them are answers (evaluated on a ten-step scale) to the question: "Please think about the activities and courses of the faculty in which you teach and note the following aspects with notes from 1 to 10 where 1 means «total disagreement», and 10 indicates «total agreement»". The items are: "The faculty where you teach is a very good faculty"; "The university you teach at is a very good university"; "The courses are intellectually stimulating." The fourth is the answer to the question: "Thinking about your students, which of the two statements below is closest to your opinion?" Respondents were asked to choose between two statements on a scale of 1 to 10 , where at value 1 we have the statement "None of them belong in a university" and at value 10 we have the statement "All are suitable for the university environment".

The perception of the availability of learning resources is measured based on the question "Please think about the activities and courses of the faculty in which you teach and note the following issues with grades from 1 to 10 , where 1 means «total disagreement» and 10 indicates «total agreement»». Three aspects were taken into consideration when constructing a factorial score: "The library and the services offered by it are of good quality"; "Students can access IT resources (in the faculty), when they need it"; "Students can use specialized equipment when they need it". In the analyzes, the variable is used as a factorial score.

\section{Data Analysis}

The method used is regression analysis. In the regression model we used indicators of work-related experiences. These are the indicators regarding the teachers' attitudes towards work (satisfaction) (extraction method used: Principal Axis Factoring. The explained variance: $45,51 \%$. KMO: 0,891 . The smallest community is $0,264)$ and system (confidence in the system) and regarding the overall assessment of the quality of the faculty/university (extraction method used: Principal Axis Factoring. The explained variance: 53,99 \%. KMO: 0,704. The smallest community is 0,216 ) and the perception of the availability of the teaching resources (extraction method used: Principal Axis Factoring. The explained variance: $63,383 \%$. KMO: 0,683. The smallest community is 0,398$)$.

Table no. 1

Regression coefficients predicting organizational commitment

\begin{tabular}{|c|l|l|l|}
\hline \multirow{2}{*}{} & \multicolumn{3}{|c|}{ Independent variable } \\
\cline { 2 - 4 } & \multicolumn{2}{|c|}{ Organizational commitment } \\
\hline \multirow{2}{*}{} & Confidence in the university system & &, 128 \\
\cline { 2 - 4 } & Overall evaluation of the faculty & &, 126 \\
\cline { 2 - 4 } & Perception of resource availability & &, 057 \\
\cline { 2 - 4 } & Work satisfaction & &, 284 \\
\hline
\end{tabular}

The regression model shows that the change in organizational commitment is largely explained by job satisfaction $(B=0.284, p<0.001)$. The higher the satisfaction in all its aspects (satisfaction with the remuneration, the relationship with colleagues, the work program, the activities carried out etc.), the higher the commitment.

This model also shows us that the organizational commitment increases with 
the confidence in the university system in general, with the positive overall evaluation of the faculty/university and with what is considered that there are resources for education and research in the institution.

We can say that our hypothesis regarding the correlation between organizational commitment and job characteristics is confirmed. Organizational commitment increases with confidence in the university system as a whole, with the positive overall assessment of the faculty/ university, as there are considered resources for education and research in the institution and when there is a high level of job satisfaction.

The study of commitment in higher education institutions has a dual relevance. On the one hand, just like any other organization in our time universities are also looking for solutions to develop their ability to adapt, change, innovate in order to achieve success in an increasingly unpredictable environment and with increasingly independent and assertive employees. One of the solutions for creating these competitive advantages is to stimulate organizational commitment. On the other hand, studying commitment is important, as competition from the labour market sometimes puts universities at a disadvantage as long as valuable employees can receive more generous offers from the private sector. Thus, they need to develop alternative motivational mechanisms and increase organizational commitment beyond mere extrinsic motivation.

\section{REFERENCES}

Dobbin, F., \& Boychuk, T. (1999). National employment systems and job autonomy: Why job autonomy is high in the nordic countries and low in the United States, Canada, and Australia. Organization Studies, Vol. 20, Issue 2, 257-291.

Mathieu, J. E., \& Zajac, D. M. (1990). A Review and Meta-Analysis of the Antecedents, Correlates, and Consequences of Organizational Commitment. Psychological Bulletin, Vol. 108, Issue 2, 171-194.

Meyer, J. P., \& Allen, N. J. (1997). Commitment in the workplace. Thousand Oaks, CA: Sage Publication.

Meyer, J. P., \& Allen, N. J., (1991). A Three-Component Conceptualization of Organizational Commitment. Human Resource Management Review, Vol. 1, Issue 1, 61-98.

Meyer, P. J., \& Herscovitch, L. (2001). Commitment in the workplace: Toward a general model. Human Resource Management Review, Vol. 11, 299-326.

Meyer, P. J., Irving, G., \& Allen, J. N. (1998). Examination of the combined effects of work values and early work experiences on organizational commitment. Journal of Organizational Behavior, Vol. 19, Issue 1, 29-52.

Mowday, R., Porter, L. W., \& Steers, R. M. (1982). Employee-organization linkages: The psychology of commitment, absenteeism and turnover. New York: Academic Press.

Parnell, J., \& Hatem, T. (1997). The Cultural Specificity of Management Constructs: An Empirical Examination. International Journal of Value-Based Management, Vol. 10, Issue 3, 247-271.

Sweeney, P. D., \& McFarlin, D. B. (1993). Workers' evaluations of the "ends" and the "means": An examination of four models of distributive and procedural justice. Organizational Behavior and Human Decision Processes, Vol. 55, Issue 1, 23-40.

Watson, G., \& Papamarcos, S. (2002). Social capital and organizational commitment. Journal of Business and Psychology, Vol. 16, Issue 4, 537-552.

Yoon, J., \& Thye, S. (2002). A dual process model of organizational commitment: Job satisfaction and organizational support. Work and occupations, Vol. 29, Issue 1, 97-124. 